\title{
Laggards in the global fertility transition
}

\author{
David Shapiro \\ Pennsylvania State University \\ 22 Calle Cristiano \\ Santa Fe, NM 87508 \\ USA \\ dshapiro@psu.edu \\ Andrew Hinde \\ Department of Social Statistics and Demography \\ University of Southampton \\ Southampton \\ SO17 1BJ \\ United Kingdom of Great Britain and Northern Ireland \\ Andrew.Hinde@soton.ac.uk
}

February 2020 


\title{
Laggards in the global fertility transition
}

\begin{abstract}
Between the early 1950s and the present, the global fertility transition has been nearly universal in the developing world. However, as of 2017, two countries out of the 190 countries for which the United Nations provides fertility estimates had not yet met the conventional criterion for establishing the onset of the fertility transition (a decline of at least 10 per cent from peak fertility), and another five countries did so only very recently. These are the laggards in the global fertility transition. The countries are all in sub-Saharan Africa: Chad, the Democratic Republic of the Congo, Equatorial Guinea, The Gambia, Mali, Niger, and Somalia. This paper first reviews the fertility history of these seven countries, and subsequently provides data on the timing and pace of the global fertility transition in the four major developing regions: Asia, Latin America and the Caribbean, Northern Africa, and sub-Saharan Africa. It then explores potential reasons for the slow emergence of fertility decline in each country. The paper concludes with a discussion of each country's prospects for fertility decline, which generally are weaker than those in the projections of the United Nations.
\end{abstract}




\section{Introduction}

Beginning for the most part soon after World War II and continuing up to the present, the global fertility transition has occurred in almost all countries throughout the developing world. However, among the 190 countries for which the United Nations (UN) produces estimates of fertility (United Nations 2017), there are two countries in which estimated fertility in 2010-2015 had not yet declined by at least 10 per cent since peak fertility was observed. Hence, these countries have not yet confirmed that they have begun the fertility transition according to the Princeton rule (Coale and Treadway 1986; Bongaarts and Casterline 2013). These countries are the Democratic Republic of the Congo (DRC) and Niger.

In addition, there are five countries in which fertility did not fall to 10 per cent or more below peak until 2010-2015, the most recent quinquennium for which the United Nations (2017) has produced fertility estimates: namely, Chad, Equatorial Guinea, The Gambia, Mali, and Somalia. These seven countries are the laggards in the global fertility transition. Three are in Middle Africa (the DRC, Chad, and Equatorial Guinea), a laggard sub-region that itself did not meet the 10 per cent rule until 2010-2015; three are in Western Africa (Niger, The Gambia, and Mali); and Somalia is in Eastern Africa. As of 2015, the total population of these seven countries was almost 145 million, more than half of which was in the DRC. This combined population figure represented 15 per cent of the population of sub-Saharan Africa in 2015.

In this paper, we seek to identify the factors that have contributed to the unusually slow decline in fertility among these laggard countries. There is a large body of literature on the various factors that influence the pace of fertility decline in the developing world. Women's education, infant and child mortality, economic growth, urbanisation, entry into a union, religion, 
ideal number of children, and modern contraceptive use are all factors that have been associated with the pace of fertility decline. More rapid increases in women's education, greater declines in infant and child mortality, more rapid economic growth and urbanisation, delayed entry into a union, belonging to a non-Muslim religion, more rapid declines in the ideal number of children, and the greater uptake of modern contraception are all factors that have been associated with more rapid declines in fertility.

A principal aim of this paper is, then, to compare these variables in the laggard countries with those in other countries in sub-Saharan Africa in which the fertility decline has been initiated earlier, and is ongoing. Our basic hypothesis is that the laggard countries will differ from other countries in the region on one or more of these relevant factors, and that these differences will help to account for their slow pace of fertility decline. However, before we get to that exercise, we wish to provide a descriptive analysis with comparisons between the laggard countries on the one hand, and both other countries in sub-Saharan Africa and other countries elsewhere in the developing world on the other.

We begin in the next section of the paper by presenting a review of the fertility histories of the laggard countries from the early 1950s until the present, and compare them to those of all less developed countries and all countries in sub-Saharan Africa. In each of the laggard countries, the total fertility rate (TFR) increased from the early 1950s onwards (a phenomenon observed in many developing nations in the years following World War II); reached a peak in a quinquennium as early as 1975-1980 or as late as 1995-2000, depending on the country; and has since fallen. We also discuss the status of fertility decline in the DRC and Niger. The following section provides an overview of the global fertility transition, with information on the timing of peak fertility in the different developing country regions, as well as on the pace of fertility 
decline. In brief, the data show that peak fertility tended to occur distinctly later in sub-Saharan Africa than in Asia, Latin America and the Caribbean, and Northern Africa; and that the time required for fertility to fall at least 10 per cent from that peak (i.e., an inverse indicator of the initial pace of fertility decline) was also considerably longer in most sub-Saharan African countries than in countries in other regions.

We then explore potential reasons for the slow fertility decline in each of the laggard countries. As noted above, we examine various factors that have been linked to fertility decline in previous research, including women's educational attainment, infant and child mortality, ideal number of children, levels and growth of GDP per head, Muslim representation, entry into marriage, and use of modern contraception. Levels and changes in these determinants should help explain why fertility in the laggard countries was so slow to decline from its peak level. The paper concludes with a discussion of the prospects for fertility decline in each of the countries.

\section{Fertility trends 1950-2015}

Because we wish to examine fertility over an extended period of time, we use estimates of fertility provided by the United Nations (2017). These estimates are the most comprehensive ones available, and go back to the middle of the 20th century. However, we acknowledge that because these estimates are in some cases based on limited data, they are subject to a certain degree of uncertainty. In particular, the identification of the quinquennium during which fertility reached its peak (shown for the laggards in Table 1) is subject to a comparatively high level of uncertainty. At the same time, because the estimates cover an extended period of time, we believe that the other measures that we use, such as the duration between peak fertility and achieving a 10 per cent decline from peak fertility - a process that takes a considerable amount of time - are less susceptible to measurement error. 
A related data issue is our use of the relative decline to confirm the onset of the fertility transition (10 per cent below peak). We do so because it is a commonly used measure. An alternative would be to focus on the absolute decline. For example, we could examine countries where the TFR remains above a certain level. If we had looked instead at countries that had a TFR of 6.00 or above in 2010-2015, we would still have included five of our laggard countries plus Burundi, but we would not have included Equatorial Guinea or The Gambia. Our focus is on fertility decline; and in Burundi the estimated TFR declined from 7.55 to 6.00. In our view, such a substantial decline is not indicative of a laggard country.

As Table 1 shows, in the early 1950s, the TFRs of the laggards ranged from about 5.3 to 7.3 for all seven countries. In the next $25-45$ years, the TFRs rose in each country, and then subsequently fell. The declines from peak fertility to $2010-2015$ were 5.5 per cent in the DRC, four per cent for Niger, 15 per cent in Chad, 17 per cent in Equatorial Guinea, 11 per cent in The Gambia and in Mali, and 14 per cent in Somalia. The last column shows that the DRC, the thirdlargest country in terms of population in the region, is the only large country in the group; while Niger, Mali, Chad, and Somalia are of medium size; and Equatorial Guinea and The Gambia are quite small.

[Table 1 about here]

In all of these countries, peak fertility was followed by monotonically declining fertility, in some cases for as long as 35 years. Indeed, monotonically declining fertility across quinquennia was observed throughout sub-Saharan Africa in the UN estimates, which suggests that cases of stalling fertility (Bongaarts 2008; Shapiro and Gebreselassie 2008; Ezeh et al. 2009) tend to be transient. Hence, even though as of the 2017 UN estimates the DRC and Niger had not yet met the 10 per cent threshold they needed to reach to be characterised as having initiated the 
fertility transition process, and despite the fact that the DRC experienced an increase in its estimated fertility between its 2007 Demographic and Health Survey (DHS) and its 2013-2014 DHS, it seems likely that for both countries, fertility will fall to at least 10 per cent below peak fertility in the near future. Indeed, this estimate is in line with the UN projections (2017), which anticipate that the DRC will reach the 10 per cent threshold during the 2015-2020 quinquennium, and that Niger will reach this level in 2020-2025.

Figure 1 shows the history of fertility since 1950 for each country, as well as averages for less developed countries and for sub-Saharan Africa. The figure is very crowded, but close examination reveals several interesting phenomena.

[Figure 1 about here]

Consider first the laggard countries. The increases from the early 1950 s to peak fertility levels, which were reached during the last quarter of the $20^{\text {th }}$ century, were generally modest (less than 10 per cent), ranging from three to eight per cent for four of the countries - but were as high as 13 per cent for the DRC, 20 per cent for The Gambia, and 21 per cent for Chad. Various explanations have been proposed for this phenomenon of increasing fertility prior to the onset of fertility decline. One contributing factor was the shortening of durations of breastfeeding and postpartum abstinence in the absence of the adoption of contraception (Romaniuk 1980; Lesthaeghe 1984). Second, it has been argued that the colonial economy, with its desire for cash crops, increased the demand for labour, and thereby encouraged high fertility (Mbacké 1994). Third, during the period under consideration, public health campaigns aimed at combating venereal disease (see, for example, Bruaux et al. 1957) served to reduce infertility among various ethnic groups throughout the region, and thereby contributed to increasing fertility. For the DRC, an important share of the increase in fertility is attributable to declining sterility (Tabutin 1982). 
For Chad as well, which also had had ethnic groups suffering from infertility (Retel-Laurentin 1974), declining sterility is likely a contributing factor in the increase in fertility. Although Cameroon is not one of the laggard countries, it is interesting to note that the Cameroon Fertility Survey in 1978 found that the proportions of women who were childless were over 20 per cent in the 50-54 age group, but were only 10-15 per cent in the 25-39 age group (Santow and Bioumla 1984). In the northern part of Cameroon, which is geographically adjacent to the most populous regions of Chad, primary sterility among women aged 50-54 was higher than the national average.

The duration of fertility increases after the early 1950s was typically quite substantial. In Chad, fertility increased for 45 years; and in the DRC, fertility increased slowly for 35 years. In Equatorial Guinea and Niger, modest increases lasted for 30 years; and in Mali, the TFR rose to above seven in 15 years, and then held steady for another 20 years. The increasing trend in The Gambia lasted for 25 years. In Somalia, the TFR was stable at 7.25 over a 20 -year period starting in the 1950s, then declined slightly, and subsequently increased over a 20 -year period.

Declines in fertility following the peak have varied in their speed. Here, we use the duration from peak fertility to a level representing a decline of 10 per cent or more from that peak as an inverse measure of the initial pace of fertility decline (for the DRC and Niger, we use the projected quinquennium at which the 10 per cent decline will be realised). In Chad and Somalia, this decline occurred in 15 years; and in the DRC and Mali, the duration of the decline is estimated at 20 years. Equatorial Guinea took 25 years to achieve a 10 per cent fertility decline. Very slow declines to this level from the peak are observed in The Gambia, where the decline took 35 years; and in Niger, where the decline is estimated to take 40 years. 
On average, then, the duration of a 10 per cent decline in fertility from its peak was just over 24 years for these countries. For the remaining countries in sub-Saharan Africa, the corresponding unweighted mean duration was just under 19 years. As we shall see below, the pace of fertility decline in the region following its onset was slow compared to elsewhere in the developing world.

A comparison of the fertility of these laggard countries with that of all developing countries shows that the downturn in fertility took place much sooner in the latter (beginning in the early 1970s) than in the former (beginning anywhere from the late 1970s to the early 2000s, with the median being in the early 1990s, or 20 years following the downturn in all developing countries). Likewise, the fertility decline in sub-Saharan Africa did not start until the 1980s; in addition, it has been much slower than the fertility decline elsewhere in the developing world (Shapiro and Hinde 2017). Within sub-Saharan Africa, Middle Africa is the laggard region. Prior to the early 1980s, fertility in Middle Africa was below that of sub-Saharan Africa, largely as a consequence of infertility in the DRC and elsewhere in the region (Retel-Laurentin 1974; Lesthaeghe 1984; Shapiro et al. 2017). But after that point, fertility in Middle Africa increased continuously for a decade, reaching almost the peak of just under 6.8 that was realised in the entire region. The fertility decline did not begin in Middle Africa until the early 1990s.

\section{The timing of peak fertility}

In this section, we examine the timing of the onset of the fertility transition, as demarcated in each country by the period following the realisation of its peak level of fertility, and we compare the timing of peak fertility in the four different regions consisting of developing countries. Calculations are weighted with the populations of each country. In addition, we examine the duration required for each country to reach a level of total fertility that is at least 10 per cent 
below its peak fertility level, as an inverse indicator of the pace of fertility decline once it has begun. We also compare the regions on this measure.

Figure 2 shows the percentage frequency distributions of the quinquennium in which peak total fertility was realised for the populations in the countries in each of the four regions. It is clear that, as expected, sub-Saharan Africa was the laggard among these regions in terms of the timing of the initiation of the fertility decline; with the fertility decline starting earlier in Latin America, Northern Africa, and Asia. The median quinquennium of peak fertility was 1955 1960 for Latin America, compared to 1960-1965 for Northern Africa, 1965-1970 for Asia, and 1980-1985 for sub-Saharan Africa.

[Figure 2 about here]

For the vast bulk of the population of Latin America, peak fertility was reached during the period from 1950 to 1965 . In Northern Africa, peak fertility occurred in 1955-1970; while in Asia, peak fertility was realised in countries with more than a third of the region's population during the late 1950s, and in countries with more than half of the region's population in the late 1960s. In contrast, in sub-Saharan Africa, peak fertility was not reached for more than 40 per cent of the region's population until 1980-1985. Indeed, whereas in the other three regions, peak fertility had been realised by 1980; in sub-Saharan Africa, 60 per cent of the population experienced peak fertility in 1980 or later. Hence, based on the median quinquennia at which peak fertility was reached, we can state that fertility decline at the regional level began in the early 1960s in Latin America, in the late 1960s in Northern Africa, in the early 1970s in Asia, and in the late 1980s in sub-Saharan Africa.

The weighted percentage distributions of the duration between hitting the peak fertility level and reaching a level of fertility that is at least 10 per cent below the peak are shown in 
Figure 3. ${ }^{1}$ In Sub-Saharan Africa, fertility has declined much more slowly than it has elsewhere: the average duration until fertility has fallen by at least 10 per cent from its peak level is 20.6 years in sub-Saharan Africa, compared to 14.5 years in Latin America, 12.1 years in Asia, and 14.9 years in Northern Africa.

[Figure 3 about here]

When that duration is 10 years or less, the average annual decline in fertility is one per cent (or more). When we look at the countries with comparatively rapid initial levels of fertility decline, we see that less than three per cent of the population of the 50 countries in sub-Saharan Africa (primarily from Malawi, Congo, and Namibia) fall into this group. By comparison, while less than three per cent of the population in Northern Africa (Libya) also experienced rapid fertility decline, more than 50 per cent of the population in Asia and 34 per cent of the population in Latin America had rapid initial levels of fertility decline. Conversely, while it took 25 years or more for fertility to decline from its peak by 10 per cent for only two per cent or less of the population in Latin America, Asia, and North Africa; this was the case for almost 17 per cent of the population in sub-Saharan Africa.

\section{Factors influencing fertility}

In this section, we review a variety of socio-economic and demographic factors that have been linked to fertility and fertility transition in sub-Saharan Africa and elsewhere in the developing world. Garenne (2018) has shown that contraceptive use is pertinent to the pace of fertility decline in the region, and Shapiro (2012) has emphasised that women's education is also a key socio-economic factor influencing fertility. Rutstein (2000) has documented that mortality is

\footnotetext{
${ }^{1}$ The data reported in both Figures 2 and 3 and in the text use population weights from the year corresponding to the onset of fertility decline in each region - i.e., from 1960 for Latin America, 1965 for Northern Africa, 1970 for Asia, and 1985 for sub-Saharan Africa. As a robustness check, we also did calculations using 1980 as the base year for all four regions. The results were very similar.
} 
declining in sub-Saharan Africa, and Shapiro and Tenikue (2017) have shown that declining infant and child mortality and increasing women's education are important factors contributing to fertility decline in the region. Bongaarts and Casterline (2013) and Casterline and AgyeiMensah (2017) have stressed the influence on fertility of fertility desires, as reflected in the ideal number of children. Sub-Saharan Africa is characterised by particularly strong fertility desires.

Shapiro (2019) has shown that after controlling for women's education and numerous other factors, Muslim women tend to have a higher ideal number of children than non-Muslim women. This observation reflects stronger preferences for children among Muslim than among non-Muslim women, and is expected to be associated with slower fertility declines. ${ }^{2}$ Antoine (2006) has documented changes in marital status in multiple African capital cities; and more broadly, Shapiro and Gebreselassie (2014) have documented the contribution of reduced nuptiality in the region to declining fertility. With respect to economic conditions, historical evidence shows that economic growth and development are associated with declining fertility. At the same time, however, Eloundou-Enyegue et al. (2000) and Shapiro (2015) have provided evidence indicating that adverse economic conditions in sub-Saharan Africa have in some cases appeared to contribute to more rapid fertility decline. In the context of the Easterlin framework for fertility analysis (Easterlin 1975; Easterlin and Crimmins 1985), these various factors constitute both background factors and proximate determinants.

\footnotetext{
${ }^{2}$ For example, consider the case of Nigeria, a country with substantial numbers of Muslims and nonMuslims. In the Nigeria 2013 DHS, regression analysis shows that after controlling for women's education, marital status, and numerous other factors linked to the ideal number of children, Muslim women have a significantly higher ideal number of children than their non-Muslim counterparts; with the differential being well over one child.
} 
Table 2 shows the values of variables representing these factors for the seven laggard countries, as of the latest DHS in each country. ${ }^{3}$ It also shows the averages for these variables from a group of 34 other countries in the region, allowing for a comparison of the laggards with a substantial number of other sub-Saharan countries, all of which are farther along in their fertility transitions. ${ }^{4}$ In addition, the estimated TFRs from the United Nations (2017) for 20102015 are included.

\section{[Table 2 about here]}

There is considerable variation among the laggard countries in each of the variables in the table, except for those pertaining to modern contraceptive use, all of which are low. On average, modern contraceptive use is only about a quarter to a third as high in the laggard countries as it is in the group of comparison countries. Education is especially low in Niger, Mali, Chad, and Equatorial Guinea; while it is high in the DRC. Compared to the averages for the non-laggard countries, the mean number of years of schooling is higher, and the percentage with no schooling is lower in the DRC. However, the percentage with secondary education is substantially lower in the DRC than the average for the countries that are farther advanced in their fertility transitions. Moreover, as has been shown elsewhere (Shapiro 2012; Shapiro and Tambashe 2017), in the DRC and in other countries in the region, it is at the secondary schooling level that distinct declines in fertility as schooling increases can be observed.

\footnotetext{
${ }^{3}$ As Somalia has never had a DHS, much of the data for Somalia are not available. The demographic measures that are available come from the United Nations (2017) estimates, and the source for the percentage Muslim is the Central Intelligence Agency (CIA) World Factbook (2017), which indicates that Islam is the official religion of Somalia.

${ }^{4}$ The comparison group of 34 countries excludes several very small countries in the region.
} 
Mortality is highest in Somalia, Chad, Equatorial Guinea, and Niger; and lowest by far in The Gambia. Average mortality in the comparison countries is lower than that in all of the laggard countries except The Gambia.

The average ideal number of children is around six children for four of the six countries for which this variable is available. In the DRC and Mali, this number is exceeded by actual fertility; while in both Equatorial Guinea and The Gambia, the mean ideal number of children is greater than the TFR. Chad and Niger are the outliers here, with exceptionally high mean ideal numbers of children. The mean ideal number of children of 4.5 found among the comparison countries is substantially lower than the corresponding means for each of the laggard countries.

In five of the seven countries, 90 per cent or more of the population is Muslim; and almost two-thirds of women in Chad are Muslim. Only the DRC has almost no Muslim population. In the comparison countries, not quite 30 per cent of the population is Muslim, on average.

In Niger and Mali, 95 per cent or more of women aged 15-49 years are in a union, compared to about 75 per cent of women in Chad and Equatorial Guinea, and about 65 per cent of women in The Gambia and the DRC. All of these figures exceed the mean of 61 per cent for the comparison countries.

The median age at first marriage among women aged 25 years and older is only about 16 years in Niger and Chad and 17 years in Equatorial Guinea, compared to 18-19 years in the DRC, The Gambia, and Mali. And the mean of the median age at first marriage for the laggards is almost 2.5 years lower than that for the comparison group, which is just under age 20 years.

GDP per head, based on data from the World Bank, ranges from a little over $\$ 700$ to a little more than $\$ 2,000$ for five of the six countries with data available. The mean for these 
countries is just under $\$ 1,200$. Equatorial Guinea is an anomaly; it has substantial income from petroleum which, in conjunction with its small population, results in a very high GDP per head. But since the income from oil is controlled by the president and does not benefit the general population, the country's very high GDP per head has nothing to do with the economic wellbeing of the population (CIA 2018).

The average GDP of the five countries with meaningful data on GDP per head is not quite a third of that of the comparison countries. Looking at the growth in GDP per head during the five years prior to the measurement of fertility in the DHSs, we see that it was positive but modest in the laggard countries, ranging from three to 13 per cent, and averaging almost nine per cent. ${ }^{5}$ By comparison, among the other countries, recent growth in GDP per head has been more varied, with a few countries showing declines. Overall, however, the average growth rate is 13 per cent.

In sum, the laggard countries are distinguished in numerous important ways from the other countries in sub-Saharan Africa that are more advanced in the fertility transition. With the notable exception of the DRC, they have distinctly lower educational attainment and substantially higher proportions Muslim than the comparison countries. These countries also have higher ideal numbers of children, lower GDP per head and slower recent growth in this measure, somewhat higher infant and child mortality, higher proportions in a union, an earlier age at first union, and lower use of modern contraception. All of these differences help to explain the higher fertility in the laggard countries. Next, we consider the prospects for fertility decline in each of these countries in view of their characteristics, as shown in Table 2.

\section{Prospects for fertility decline}

\footnotetext{
${ }^{5}$ A DHS measures fertility during the three years prior to the survey. Hence, this measure looks at the growth in GDP per head for the period from three to eight years prior to the DHS.
} 
We begin with the two countries that have not yet achieved a 10 per cent decline from their peak fertility level. As we noted in the preceding section, the Democratic Republic of the Congo has comparatively high women's educational attainment, which would normally be expected to facilitate fertility decline. However, as Smith-Greenaway (2015) has shown, there is only a weak correlation between education and literacy in much of sub-Saharan Africa. She has found that in the DRC, fewer than half of women with six years of schooling have full reading skills (Fig. 1b, p. 1022). Because of the economic difficulties the DRC has experienced over much of the past 30 years, public funding for education has been low (Shapiro et al. 2017). This could mean that problems with school quality limit the effects on fertility of school quantity.

Furthermore, a distinguishing characteristic of Congolese women compared to their welleducated counterparts in other countries is that they have a high ideal number of children. More generally, conditional on their educational attainment, Congolese women tend to have a high ideal number of children (Shapiro 2018). Guengant et al. (2014), in their analysis of the DRC, describe the "greatness syndrome"; whereby the country's vast area, mineral wealth, and other resources are seen by both elites and much of the general population as making fertility control unnecessary. Thus, all that is needed, in their view, is better management of existing resources. This syndrome - which is similar to the perceived effects of abundant resources in a vast country found to contribute to very high fertility of French Canadians in the 17th and 18th centuries (Charbonneau et al. 2000) - may well be a contributing factor in the high levels of ideal number of children; and, hence, in the country's high fertility.

Absent a weakening of this greatness syndrome, the best option for ensuring continued and accelerated fertility decline in the DRC is - in addition to continued increases in women's education (especially at the secondary level and above) and continued reductions in infant and 
child mortality - economic development that generates demand in the labour market for individuals with useful skills (Lachaud 1994 provides a short but still-relevant critique of education and training in Africa). Since the acquisition of skills requires human capital investments, this shift would contribute to fertility reduction as parents increasingly opt for "quality" in the quality-quantity trade-off.

Niger is a very different case. It has the highest fertility in the world at present. More than 80 per cent of women of reproductive age in Niger have never been to school, and only nine per cent have secondary or higher education. As a Muslim country, women in Niger share the slightly higher fertility preferences found among Muslims, other things being equal (Shapiro 2018). Indeed, the mean ideal number of children is extraordinarily high in Niger, at 9.2 per woman. With such high actual fertility and an even higher ideal number of children, in conjunction with a resource-poor environment in which opportunities for out-migration in hard times have become considerably more limited, Niger appears to be a Malthusian disaster waiting to happen. ${ }^{6}$ Casterline and Agyei-Mensah (2017) have found that, uniquely even among the countries of West and Middle Africa, in Niger, there is almost no desire to stop childbearing even among women with six children.

Chad has a profile that is similar to (but is less extreme than) that of Niger: the country has low education, high infant mortality, a very high ideal number of children, and a very low age at entry to marriage. Despite the absence of conditions favourable to reduced fertility, Chad has seen relatively rapid declines in its TFR in the last two quinquennia. In the last estimate,

\footnotetext{
${ }^{6}$ Although demographers have been writing in this vein about the Sahel region for 50 years, the threatened disaster has yet to materialise. The ability of the Sahel to accommodate very rapid population growth during the past 20-30 years without widespread increases in malnutrition or major famine is remarkable. For a recent discussion of these issues, see Potts et al. 2013)
} 
fertility in Chad was 1.1 children below its peak, but was still high at 6.3. Given the country's profile, it remains to be seen if the recent rapid declines will continue.

Equatorial Guinea has low education and comparatively high mortality, is 90 per cent Muslim, is tied for the lowest rate of use of modern contraception, and has an ideal number of children in excess of actual fertility. All of these factors serve to promote high fertility. Despite these conditions, the estimated recent fertility declines in Equatorial Guinea have been increasing in magnitude. While the UN projections foresee continued more-than-trivial fertility declines in this country, the underlying factors are not propitious.

Compared to the other laggard countries, The Gambia is intermediate with respect to education, has the lowest mortality, and has a comparatively high age at first union and a low percentage of women in a union. These factors are favourable to ongoing fertility decline. But on the other side of the ledger, the population is almost entirely Muslim; and, most notably, the country has a mean ideal number of children in excess of its TFR. In line with the UN projections generally for the countries in sub-Saharan Africa, continued declines in fertility are anticipated for The Gambia in the coming years.

Mali has low education and a high percentage of women in a union, and is more than 90 per cent Muslim. These fertility-promoting factors are offset somewhat by a moderately high mean age at first union and the fact that the TFR in the country exceeds the mean ideal number of children by half a child. This latter point suggests that there may be opportunities for effective family planning to assist women in reaching, but not exceeding their fertility goals. ${ }^{7}$

\footnotetext{
${ }^{7}$ The TFR being in excess of the mean ideal number of children does not guarantee that parents seek to reduce the number of births, since in the face of traditionally high infant and child mortality, realised fertility may include births that constitute insurance or replacement motives for childbearing. However, it seems likely that in this situation, some women would wish to limit their fertility.
} 
Due to its unstable political situation, a Demographic and Health Survey has never been conducted in Somalia. Hence, only very limited information about this country is available. The existing data show that compared to other the laggard countries, Somalia has high mortality, a very high percentage Muslim, and the second-highest TFR. These factors are all conducive to slow fertility decline; but again, the UN projections indicate that the country is experiencing an ongoing decline that is not slow.

\section{Concluding remarks}

This paper has examined fertility trends in the seven countries that lag behind the rest of the world in undergoing the fertility transition. We have also discussed the social, economic, and cultural characteristics of these countries. We might ask whether there is any single characteristic that separates these seven countries from the rest of the countries in sub-Saharan Africa. The analysis in the preceding section suggests that this is not the case. As we have seen, fertility is associated with many different factors that, when taken together, can be viewed as a multidimensional space within which each country occupies a unique position. A certain zone of this space is associated with a resistance to fertility decline. Countries in this zone tend to have fertility-promoting values on most - though not necessarily all - of the factors we have considered.

Over the past five decades, most of the countries of the world have moved out of this zone. The laggards are the last countries to do so, and one or two of them are still confined within it.

In the end, however, the laggards will shift their position away from the high fertility zone, and join the other countries of the world in the global fertility transition. But the continuing high fertility of the laggards will contribute for some time to come to the ongoing status of subSaharan Africa as the lone remaining high-fertility region in the world. Moreover, because 
fertility in the laggard countries is so high, further delays in the onset and progress of the fertility transition have the potential to greatly to augment population growth in these countries. To take one example, Niger currently has a population of around 23 million. In the next 50 years, mainly depending on how quickly fertility declines, the UN estimates its population could be anywhere between around 80 and 130 million; and the corresponding range for the DRC is 200-350 million people (United Nations 2019). ${ }^{8}$ The rate at which the fertility transition in these laggard countries progresses will, therefore, have a substantial impact on future population growth in sub-Saharan Africa, and will affect the size of the challenge of improving human well-being in this region.

\section{Acknowledgments}

Research assistance was provided by Liwei Zhang with support from the Bates-White Research Experiences for Undergraduates Program of the Penn State Department of Economics. Responsibility for the contents of this paper rests solely with the authors.

\section{References}

Antoine, P. 2006. Analyse biographique de la transformation des modèles matrimoniaux dans quatre capitales africaines: Antananarivo, Dakar, Lomé et Yaoundé. Cahiers Québecois de Démographie 35(2): 5-38.

Bongaarts, J. 2008. Fertility transition in developing countries: progress or stagnation? Studies in Family Planning 39(2): 105-110.

Bongaarts, J. and Casterline, J. 2013. Fertility transition: is sub-Saharan Africa different? Population and Development Review 38 (Supplement 1): 153-168.

\footnotetext{
${ }^{8}$ These ranges are based on 80 per cent prediction intervals. Although assumptions about mortality and migration play a minor part, the main factor affecting the forecasts is the future fertility trend.
} 
Bruaux, P., Cerf, J. and Lebrun, A. 1957. La lutte contre les affections vénériennes à Léopoldville. Annales de la Société Belge de Médicine Tropicale 37(6): 801-813.

Casterline, J. and Agyei-Mensah, S. 2017. Fertility desires and the course of fertility decline in sub-Saharan Africa. Population and Development Review 43 (Supplement 1): 84-111.

Central Intelligence Agency. 2017. World Factbook.

https://www.cia.gov/library/publications/the-world-factbook/geos/so.html. Accessed 7 Sept. 2017.

Central Intelligence Agency. 2018. World Factbook. https://www.cia.gov/library/publications/the-world-factbook/geos/ek.html. Accessed 28 March 2018.

Charbonneau, H., Desjardins, B., Légaré, J. and Denis, H. 2000. The Population of the St. Lawrence Valley, 1608-1760. In A Population History of North America, eds. M. Haines and R. Steckel, 99-142. Cambridge, UK: Cambridge University Press.

Coale, A.J. and Treadway, R. 1986. A summary of the changing distribution of overall fertility, marital fertility, and proportion married in the provinces of Europe. In The Decline of Fertility in Europe, eds. A.J. Coale and S.C. Watkins, 31-181. Princeton: Princeton University Press.

Easterlin, R. 1975. An economic framework for fertility analysis. Studies in Family Planning 6(1): 54-63.

Easterlin, R. and Crimmins, E. 1985. The Fertility Revolution: A Supply-Demand Analysis. Chicago: University of Chicago Press.

Eloundou-Enyegue, P., Stokes, C.S. and Cornwell, G. 2000. Are there crisis-led fertility declines? Evidence from central Cameroon. Population Research and Policy Review 19(1): 4772 .

Ezeh, A., Mberu, B.U. and Emina, J.O. 2009. Stall in fertility decline in Eastern African Countries: regional analysis of patterns, determinants and implications. Philosophical Transactions of the Royal Society B 364(1532): 2971-2974.

Garenne, M. 2018. Family Planning and Fertility Decline in Africa: From 1950 to 2010. http://dx.doi.org/10.5772/intechopen.71029.

Guengant, J-P, Mangalu, J. and Banda, N.M. 2014. Bénéficier du Dividende Démographique? Replacer la Population au Centre des Trajectoires de Développement de la République Démocratique du Congo. Kinshasa: PARSS, AFD, IRD. 
Lachaud, J-P. 1994. Poverty and the urban labour market in sub-Saharan Africa: A comparative analysis. In Jean-Pierre Lachaud, The Labour Market in Africa, 1-82. Geneva: International Labour Organization, International Institute for Labour Studies.

Lesthaeghe, R. 1984. Fertility and its proximate determinants in sub-Saharan Africa: the record of the 1960s \& 70s. Brussels: Vrije Universiteit Brussel Interuniversity Program in Demography, Working Paper 1984-2.

Mbacké, C. 1994. Review: family planning programs and fertility transition in sub-Saharan Africa. Population and Development Review 20(1): 188-193.

Potts, M., Henderson, C. and Campbell, M. 2013. The Sahel: a Malthusian challenge? Environmental and Resource Economics 55(4): 501-512.

Retel-Laurentin, A. 1974. Infécondité en Afrique Noire: Maladies et Conséquences Sociales. Paris: Masson \& Co.

Romaniuk, A. 1980. Increase in natural fertility during the early stages of modernization: Evidence from an African case study, Zaire. Population Studies 34(2): 293-310.

Rutstein, S.. 2000. Factors associated with trends in infant and child mortality in developing countries during the 1990s. Bulletin of the World Health Organization 78: 1256-1270.

Santow, G. and Bioumla, A. 1984. An evaluation of the Cameroon Fertility Survey 1978. World Fertility Survey Scientific Reports no. 64. Voorberg: International Statistical Institute.

Shapiro, D. 2012. Women's education and fertility transition in sub-Saharan Africa. Vienna Yearbook of Population Research 2012 10: 9-30.

Shapiro, D. 2015. Enduring economic hardship, women's education, marriage and fertility transition in Kinshasa. Journal of Biosocial Science 47(2): 258-274.

Shapiro, D. 2018. Emerging preferences for low fertility in sub-Saharan Africa: an exploratory study. Revised version of paper presented at the 2016 Annual Meeting of the Population Association of America.

Shapiro, D. 2019. Adjusting for Nonnumeric Responses Regarding Ideal Number of Children: Evidence from Sub-Saharan Africa. Paper presented at the Annual Meeting of the Population Association of America, Austin, Texas.

Shapiro, D. and Gebreselassie, T. 2008. Fertility transition in sub-Saharan Africa: falling and stalling. African Population Studies 23(1): 3-23.

Shapiro, D. and Gebreselassie, T. 2014. Marriage in sub-Saharan Africa: Trends, determinants, and consequences. Population Research and Policy Review 33(2): 229-255. 
Shapiro, D. and Hinde, A. 2017. On the pace of fertility decline in sub-Saharan Africa. Demographic Research, 37(40): 1327-1338.

Shapiro, D. and Tambashe, B. 2017. Fertility, ethnicity, and education in the Democratic Republic of the Congo. African Population Studies 31(1): 3253-3270.

Shapiro, D. and Tenikue, M. 2017. Women's education, infant and child mortality, and fertility decline in urban and rural sub-Saharan Africa. Demographic Research, 37(21): 669-708.

Shapiro, D., Tambashe, B. and Romaniuk, A. 2017. The third biggest African country: The Democratic Republic of the Congo. In Africa's Population: In Search of a Demographic Dividend, eds. H. Groth and J.F. May, 71-86. Springer International Publishing AG.

Smith-Greenaway, E. 2015. Educational attainment and adult literacy: A descriptive account of 31 sub-Saharan Africa countries. Demographic Research, 33(35): 1014-1033.

Tabutin, D. 1982. Evolution régionale de la fécondité dans l'ouest du Zaïre. Population, 37(1): 29-50.

United Nations. 2017. World Population Prospects: The 2017 Revision, DVD Edition. New York: United Nations Department of Economic and Social Affairs, Population Division.

United Nations. 2019. World Population Prospects: The 2019 Revision. New York: United Nations Department of Economic and Social Affairs, Population Division. https://population.un.org/wpp/Graphs/Probabilistic/POP/TOT/562. 
Figure 1. Total fertility rates, laggard countries, less developed countries, and sub-Saharan Africa, 1950-2015

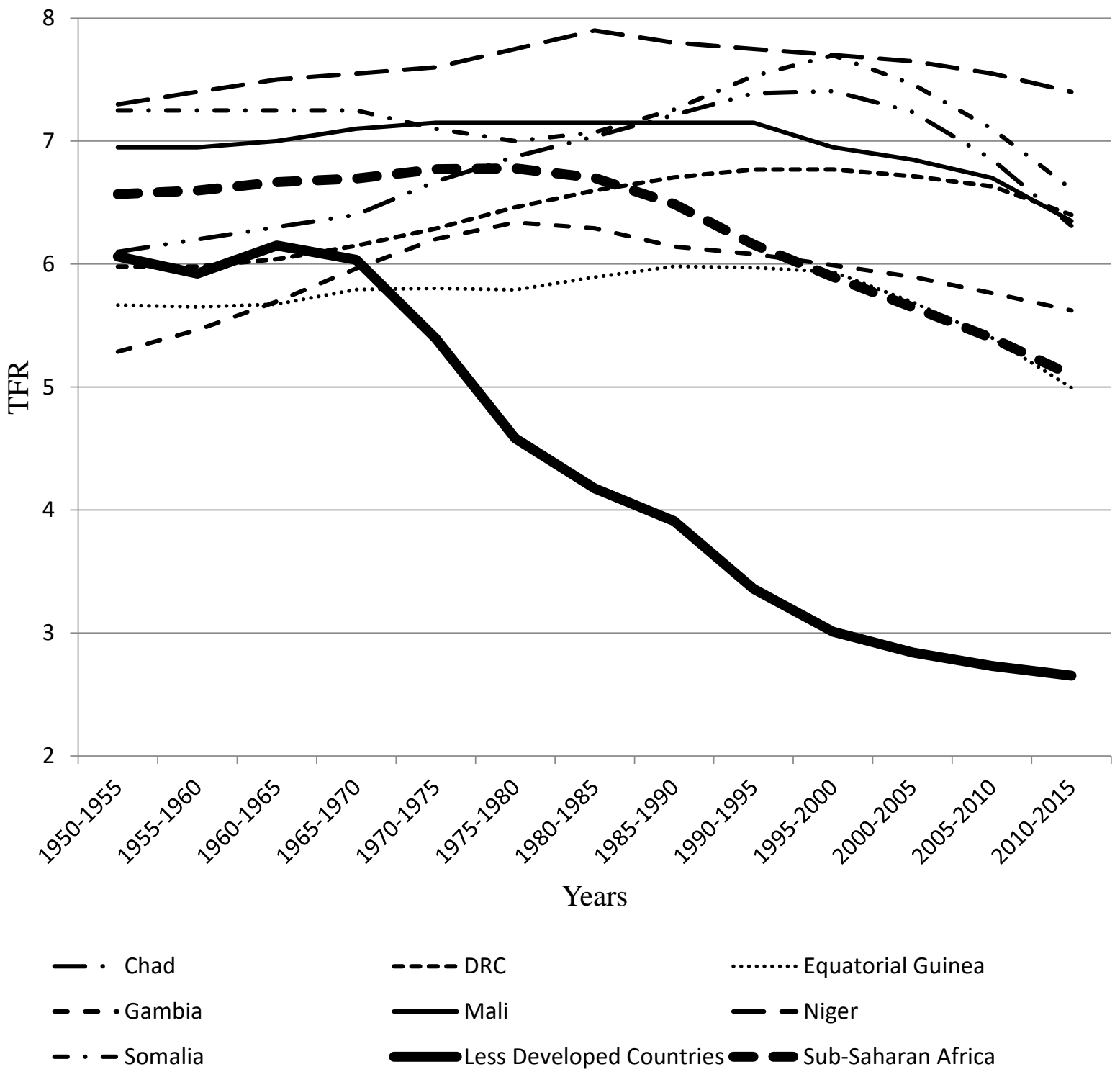


Figure 2. Quinquennium of peak fertility, by region

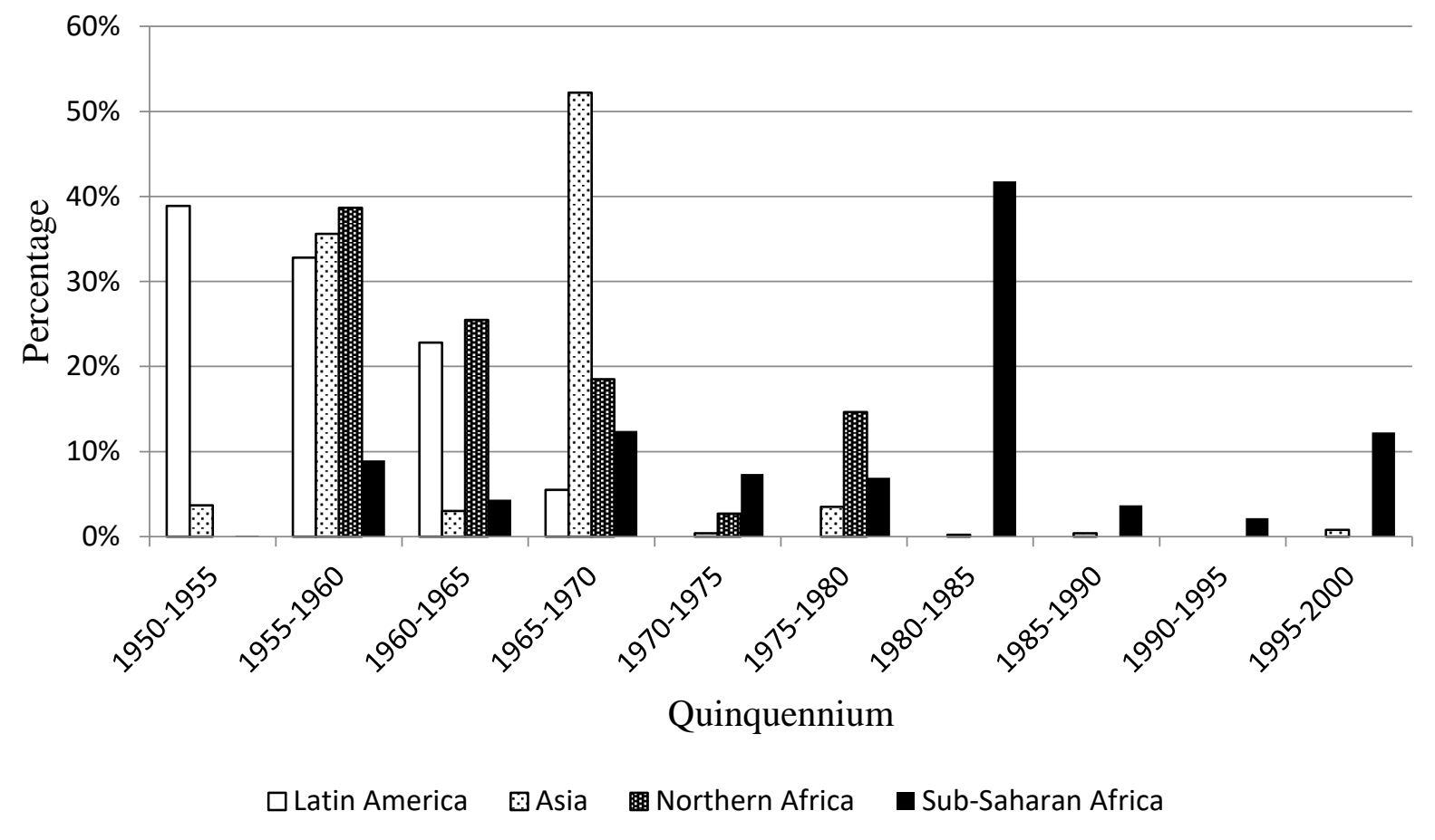


Figure 3. Duration until $10 \%$ decline from peak fertility, by region

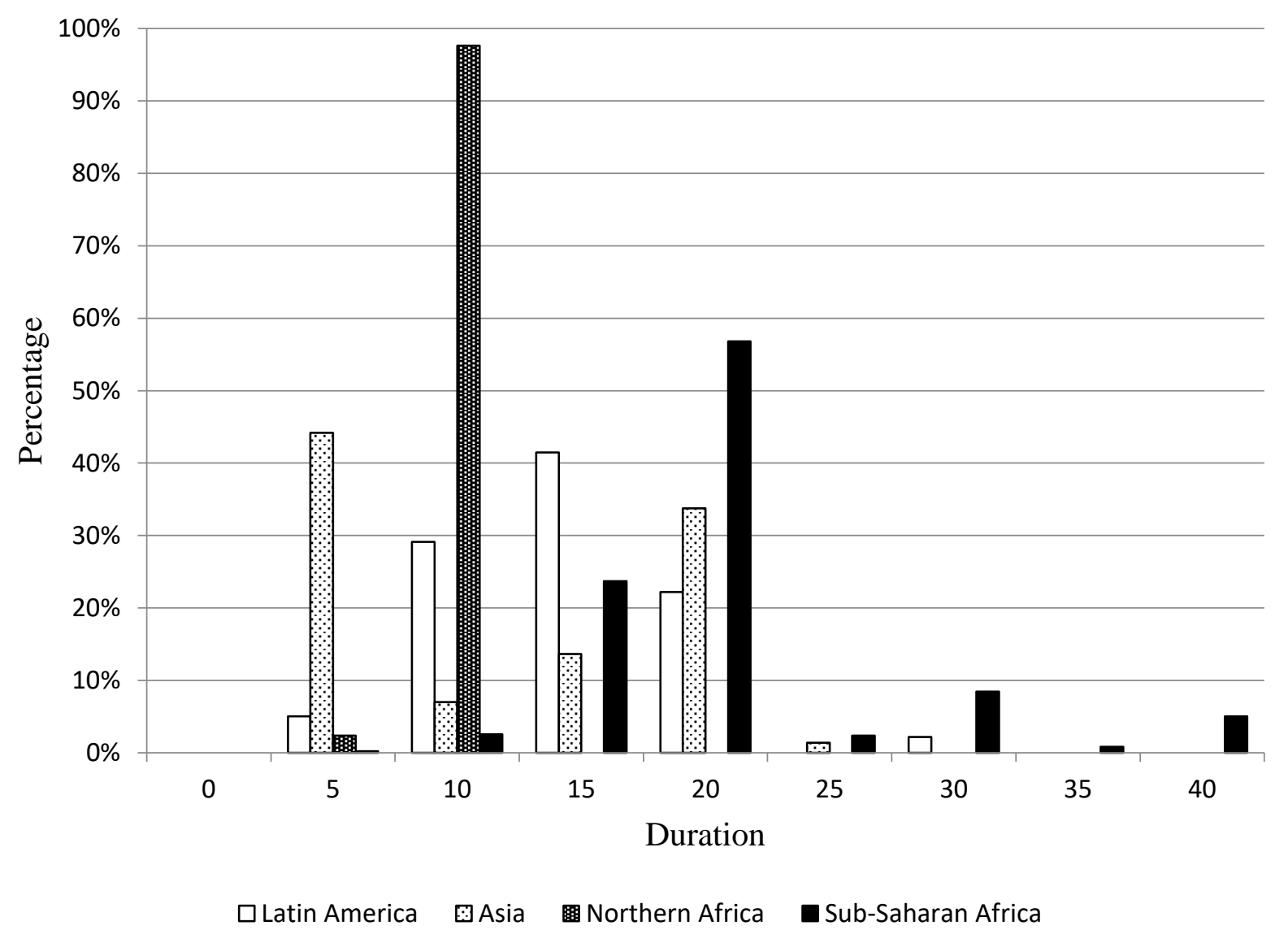


Table 1. Total fertility rates (TFRs) in 1950-1955, 2010-2015, and at peak, and quinquennium of peak

\begin{tabular}{|l|c|c|c|c|c|}
\hline Country & $\begin{array}{c}1950- \\
1955\end{array}$ & $\begin{array}{c}2010- \\
2015\end{array}$ & Peak & $\begin{array}{c}\text { Quinquennium } \\
\text { of peak }\end{array}$ & Population, \\
\cline { 1 - 1 } \cline { 6 - 6 } & & & & & $\begin{array}{c}2015 \\
\text { (millions) }\end{array}$ \\
\hline Chad & 6.10 & 6.31 & 7.41 & $1995-2000$ & 14.0 \\
\hline $\begin{array}{l}\text { Democratic Republic of the } \\
\text { Congo }\end{array}$ & 5.98 & 6.40 & 6.77 & $1990-2000^{\mathrm{a}}$ & 76.2 \\
\hline Equatorial Guinea & 5.67 & 4.99 & 5.98 & $1985-1990$ & 1.2 \\
\hline The Gambia & 5.29 & 5.62 & 6.34 & $1975-1980$ & 2.0 \\
\hline Mali & 6.95 & 6.35 & 7.15 & $1970-1995^{\mathrm{b}}$ & 17.5 \\
\hline Niger & 7.30 & 7.40 & 7.90 & $1980-1985$ & 19.9 \\
\hline Somalia & 7.25 & 6.61 & 7.70 & $1995-2000$ & 13.9 \\
\hline
\end{tabular}

${ }^{a}$ The TFR estimates were identical for 1990-1995 and 1995-2000.

${ }^{\mathrm{b}}$ The estimated peak TFR was constant for 25 years. 
Table 2. Socio-economic and demographic factors influencing fertility, latest Demographic and Health Surveys

\begin{tabular}{|c|c|c|c|c|c|c|c|c|c|}
\hline \multirow[t]{2}{*}{ Factor } & \multirow[t]{2}{*}{ Chad } & \multirow[b]{2}{*}{$\begin{array}{c}\text { Demo- } \\
\text { cratic } \\
\text { Republic } \\
\text { of the } \\
\text { Congo }\end{array}$} & \multirow{2}{*}{$\begin{array}{l}\text { Equatorial } \\
\text { Guinea }\end{array}$} & \multirow{2}{*}{$\begin{array}{l}\text { The } \\
\text { Gambia }\end{array}$} & \multirow[t]{2}{*}{ Mali } & \multirow[t]{2}{*}{ Niger } & \multirow[t]{2}{*}{ Somalia } & \multicolumn{2}{|c|}{ Averages $^{\mathrm{a}}$} \\
\hline & & & & & & & & Laggards & Others \\
\hline $\begin{array}{l}\text { Mean years of } \\
\text { schooling }\end{array}$ & 2.3 & 6.1 & 2.6 & 4.7 & 2.2 & 1.4 & NA & 3.2 & 5.6 \\
\hline $\begin{array}{l}\text { Percentage with no } \\
\text { school }\end{array}$ & 63 & 18 & 67 & 47 & 70 & 80 & NA & 58 & 28 \\
\hline $\begin{array}{l}\text { Percentage with } \\
\text { secondary+ }\end{array}$ & 15 & 48 & 19 & 40 & 17 & 9 & NA & 25 & 73 \\
\hline Infant mortality & 72 & 58 & 67 & 34 & 56 & 51 & 79 & 60 & 52 \\
\hline $\begin{array}{l}\text { Under-five } \\
\text { mortality }\end{array}$ & 133 & 104 & 123 & 54 & 95 & 127 & 131 & 110 & 82 \\
\hline $\begin{array}{l}\text { Mean ideal number } \\
\text { of children }\end{array}$ & 8.2 & 6.1 & 5.8 & 6.0 & 5.9 & 9.2 & NA & 6.9 & 4.5 \\
\hline Percentage Muslim & 65 & 2 & 90 & 97 & 92 & 80 & 100 & 75 & 28 \\
\hline GDP/head & $\$ 2,048$ & $\$ 726$ & $\$ 34,363$ & $\$ 1,599$ & $\$ 1,805$ & $\$ 863$ & NA & $\$ 1,174^{\mathrm{b}}$ & $\$ 3,999$ \\
\hline GDP/head growth ${ }^{\mathrm{c}}$ & $13 \%$ & $13 \%$ & $89 \%$ & $7 \%$ & $7 \%$ & $3 \%$ & NA & $9 \%^{\mathrm{d}}$ & $13 \%$ \\
\hline Percentage in union & 75 & 64 & 74 & 66 & 85 & 89 & $\mathrm{NA}$ & 76 & 61 \\
\hline $\begin{array}{l}\text { Median age at first } \\
\text { marriage }\end{array}$ & 16.1 & 18.7 & 17.0 & 18.6 & 18.0 & 15.7 & NA & 17.4 & 19.8 \\
\hline $\begin{array}{l}\text { Percentage using } \\
\text { modern } \\
\text { contraception }\end{array}$ & 5 & 8 & 5 & 8 & 10 & 12 & NA & 8 & 23 \\
\hline $\begin{array}{l}\text { Percentage } \\
\text { contracepting- } \\
\text { in union }\end{array}$ & 5 & 8 & 5 & 8 & 10 & 12 & NA & 8 & 32 \\
\hline TFR in $2010-2015$ & 6.3 & 6.4 & 5.0 & 5.6 & 6.4 & 7.4 & 6.6 & 6.2 & 4.6 \\
\hline
\end{tabular}

Sources: Analyses of Demographic and Health Survey country data files, DHS Statcompiler, https://data.worldbank.org/indicator/NY.GDP.PCAP.PP.KD?order=wbapi_data_valu, United Nations (2017). The sample consists of women aged 15-49 years in each country, except for age at first marriage (ages 25-49 years) and contraceptive use among women in union. NA indicates that data are not available.

${ }^{a}$ For the seven laggards and for 34 other countries in sub-Saharan Africa. In total, these 41 countries represented nearly 94 per cent of the population of sub-Saharan Africa in 2015. In some of the other countries, no DHS has been conducted; hence, for these countries, data are missing for the calculation of most averages.

${ }^{\mathrm{b}}$ The average for the laggards does not include Equatorial Guinea.

${ }^{c}$ During the five years preceding the survey's measurement of fertility.

${ }^{\mathrm{d}}$ The average figure for the laggards excludes Equatorial Guinea, which experienced substantial growth. 